Research Article

\title{
Experimental Study on Dynamic Mechanical Properties and Energy Evolution Characteristics of Limestone Specimens Subjected to High Temperature
}

\author{
Qi Ping ${ }^{1}$, ${ }^{1,2,3}$ Chuanliang Zhang, ${ }^{1,2,3}$ Haipeng Su, ${ }^{1,2,3}$ and Hao Zhang ${ }^{1,2,3}$ \\ ${ }^{1}$ State Key Laboratory of Mining Response and Disaster Prevention and Control in Deep Coal Mine, \\ Anhui University of Science and Technology, Huainan, Anhui 232001, China \\ ${ }^{2}$ Research Center of Mine Underground Engineering, Ministry of Education, Anhui University of Science and Technology, \\ Huainan, Anhui 232001, China \\ ${ }^{3}$ School of Civil Engineering and Architecture, Anhui University of Science and Technology, Huainan, Anhui 232001, China \\ Correspondence should be addressed to Qi Ping; ahpingqi@163.com
}

Received 13 April 2020; Revised 7 May 2020; Accepted 23 May 2020; Published 9 June 2020

Academic Editor: Bisheng Wu

Copyright ( 2020 Qi Ping et al. This is an open access article distributed under the Creative Commons Attribution License, which permits unrestricted use, distribution, and reproduction in any medium, provided the original work is properly cited.

To study the effect of high temperature on the dynamic mechanical properties and energy evolution characteristic of limestone specimens, the basic physical parameters of limestone specimens that cool naturally after experiencing high temperatures of room temperature $\left(25^{\circ} \mathrm{C}\right), 200^{\circ} \mathrm{C}, 400^{\circ} \mathrm{C}$, and $600^{\circ} \mathrm{C}$ were tested. In addition, compression tests with 6 impact loading conditions were conducted using SHPB device. The changes of basic physical properties of limestone before and after temperature were analyzed, and the relationship among dynamic characteristic parameters, energy evolution characteristics, and temperature was discussed. Test results indicated that, with the increase of temperature, the surface color of specimen changed from gray-black to gray-white, and its volume increased, while the mass, density, and P-wave velocity of specimen decreased. The dynamic compressive stressstrain curve of limestone specimens after different high-temperature effects could be divided into three stages: elasticity stage, yield stage, and failure stage. Failure mode of specimen was in the form of spalling axial splitting, and the degree of fragmentation increased with the increase of the temperature and incident energy. With the increase of the temperature, the reflection energy, the absorption energy, the dynamic compressive strength, and dynamic elastic modulus of rock decreased, while its transmission energy, the dynamic peak strain, and strain rate increased. The dynamic compressive strength, dynamic elastic modulus, dynamic strain, and strain rate of limestone specimens all increased with the increase of incident energy, showing a quadratic function relationship.

\section{Introduction}

Rock engineering safety problem induced by high temperature had become an important topic in rock mechanics research [1-3]. High-temperature rock mechanical behavior was different from normal temperature, and its physical and mechanical properties were closely related to the temperature; hence, studying the mechanical behavior of rock after high temperature had important theoretical and engineering significance [4-6].

Based on the response of rock to strain rate, the strength and deformation characteristics of rock after high temperature could be divided into static and dynamic aspects. Under static loads, Xi et al. [7] investigate the thermal damage characteristic of granite after different high-temperature effects, and the shear failure strength criterion of granite under thermomechanical coupling was established; in addition, test results indicated that temperature had significant effect on the failure characteristic of granite specimen. Su et al. [8] conducted the static compressive tests on fine-grained sandstone after high temperature, and the effects of temperature on static compressive strength and structure characteristics of sandstone were also investigated using X-ray diffraction and scanning electron microscope 
technique; the test found that $600^{\circ} \mathrm{C}$ could be used as a threshold temperature of strength conversion of finegrained sandstone samples. Considering the stress state of rock in engineering, $\mathrm{Xu}$ et al. [9] carried out the triaxial compressive tests on granite and studied the strength and deformation properties of granite under different confining pressures and high-temperature effects. Under dynamic loads, scholars conducted dynamic impact tests with the help of split Hopkinson pressure bar (SHPB) device to investigate the strength and deformation characteristic of rock at high strain rate. Yin et al. [10] investigate the dynamic mode I fracture toughness of granite with different temperatures and strain rates under coupling static and dynamic loads. The mechanical behavior and failure mode of biotite granite under combined action of cycle loading and high temperature $\left(20^{\circ} \mathrm{C}, 200^{\circ} \mathrm{C}, 400^{\circ} \mathrm{C}\right.$, and $\left.600^{\circ} \mathrm{C}\right)$ were studied using a modified SHPB device [11]; test results revealed that a threshold temperature for biotite granite may have existed between $400^{\circ} \mathrm{C}$ and $600^{\circ} \mathrm{C}$. Wong et al. [12] found that the peak stress and fragment size of marble sample after heating were inversely related to the heating temperature, and most of energy was dissipated through plastic deformation. Liu and $\mathrm{Xu}$ [13] conducted dynamic impact tests on marble with various high temperatures and air pressures, and the relationship between dynamic stress-strain curve characteristic and failure mode was studied.

Limestone was one of the most widely distributed mineral resources in the Earth's crust, which was the main raw material for burning lime and cement; moreover, it was also the requisite flux for steelmaking and ironmaking [14-16]. Hence, it was valuable to study the physical and mechanical properties of limestone after high temperature. Rock material was composed of mineral particles of various chemical compositions and different crystallinities, and energy was an internal factor for the destruction of rock, which was accompanied by the entire deformation and destruction process [17-19]. Additionally, energy dissipation was the driving force for the destruction of material, and rock deformation and failure could be regarded as the result of mutual conversion between different forms of energy, which produced irreversible energy dissipation [20-27]. Yin et al. [28] investigated the damage degree and energy dissipation characteristic of rock after high-temperature treatment, and results showed that, with the increase of high temperature, the reflected energy increased, while both transmitted energy and absorbed energy decreased.

From the above investigation, it could be concluded that the research results of high-temperature limestone mainly focus on the static loads, and the dynamic mechanical properties and energy dissipation of limestone were limited. In this research, the basic physical parameters, such as color, volume, mass, density, and longitudinal wave velocity of the specimen after experiencing high temperatures of room temperature $\left(25^{\circ} \mathrm{C}\right), 200^{\circ} \mathrm{C}, 400^{\circ} \mathrm{C}$, and $600^{\circ} \mathrm{C}$, were compared. Moreover, the dynamic compressive tests on sandstone after high-temperature effects were carried out with 6 impact pressures $(0.4 \mathrm{MPa}, 0.5 \mathrm{MPa}, 0.6 \mathrm{MPa}, 0.7 \mathrm{MPa}$, $0.8 \mathrm{MPa}$, and $0.9 \mathrm{MPa}$ ), and the dynamic stress-strain curves and failure modes of sandstone specimen with various test conditions were studied. Finally, the relationships among dynamic compressive strength, dynamic elastic modulus, dynamic strain, and strain rate, as well as the failure mode of sandstone specimen and temperature, were analyzed from the energy perspective.

\section{Basic Physical Properties before and after High Temperature}

2.1. Processing and High-Temperature Heating of Limestone Specimens. Rock specimens were collected from Shungeng mountain in Anhui province, China. To enhance the contrast of the test results, test specimens used were taken from the same rock block with good compactness and homogeneity [29]. According to the recommendations of the international institute of rock mechanics [30] and the China rock mechanics and engineering society's "Technical specification for testing method of rock dynamic properties" [31], the size of the limestone specimen was determined to be $50 \mathrm{~mm} \times 25 \mathrm{~mm}$. Rock sample processing equipment such as ZS-100 drilling sampler, DJ-1 rock cutting machine, and SHM-200 double-end grinder was used to core, cut, and grind and polish to control the unevenness of the two ends of rock specimen less than $\pm 0.05 \mathrm{~mm}$, and the error of the end surface perpendicular to the axis of the test piece was less than $\pm 0.25^{\circ}$, ensuring that the machining accuracy meets the test requirements.

A box-type resistance furnace equipped with an automatic temperature control system was used to heat the limestone specimen at high temperature, as shown in Figure 1. The size of the working room was $300 \mathrm{~mm} \times 200 \mathrm{~mm} \times 120 \mathrm{~mm}$, and the designed maximum heating temperature was $1200^{\circ} \mathrm{C}$. First, place limestone specimens evenly in the furnace with a certain distance between two specimens. Subsequently, the heating was performed slowly at a heating rate of $10^{\circ} \mathrm{C} / \mathrm{min}$ until reaching the set temperature. The temperature set values were $200^{\circ} \mathrm{C}, 400^{\circ} \mathrm{C}$, and $600^{\circ} \mathrm{C}$, respectively, in addition, a set of room temperature $\left(25^{\circ} \mathrm{C}\right)$ was added for comparison. In order to ensure that rock specimens were uniformly heated, temperature would keep constant temperature for $4 \mathrm{~h}$ after heating to the set temperature. Finally, the heated limestone specimens were cooled to normal temperature in the furnace by natural cooling.

\subsection{Apparent Morphological Characteristics of Specimens after} High Temperature. In this test, the apparent morphology of limestone specimens subjected to room temperature $\left(25^{\circ} \mathrm{C}\right)$, $200^{\circ} \mathrm{C}, 400^{\circ} \mathrm{C}$, and $600^{\circ} \mathrm{C}$ is shown in Figure 2. It could be noticed that the color of the limestone specimen at room temperature was gray-black; moreover, the surface color of the specimen changed significantly and become gray-white after the high temperature. When the temperature increased to $600^{\circ} \mathrm{C}$, a small amount of powder particles appeared on the surface of rock specimen, which illustrated that high temperature action showed damage effect on the structure of limestone and caused degradation of mechanical properties. 


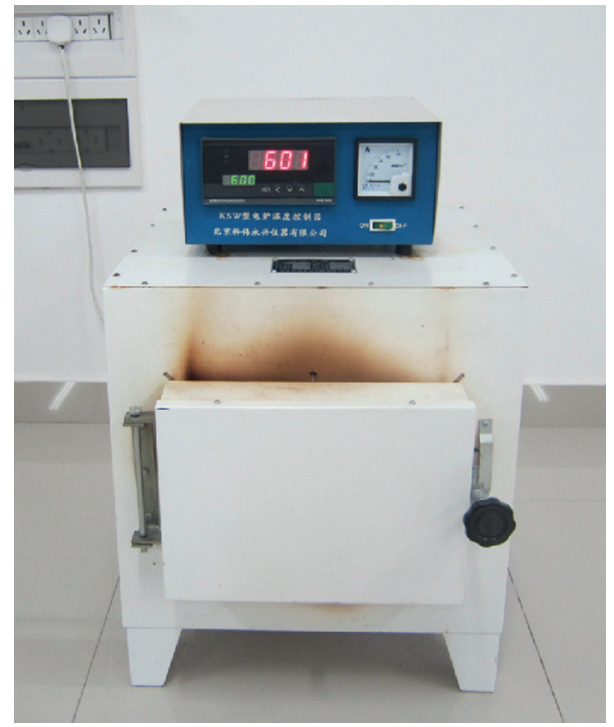

FIGURE 1: Box-type resistance furnace heated at high temperature.

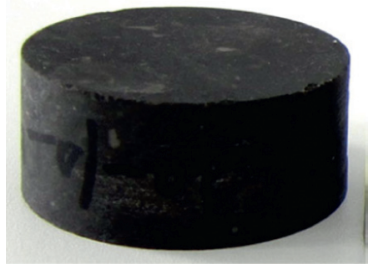

(a)

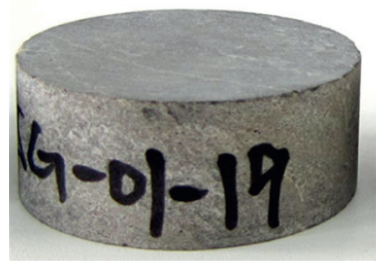

(b)

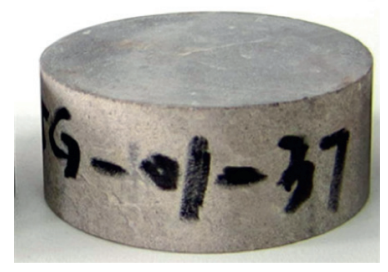

(c)

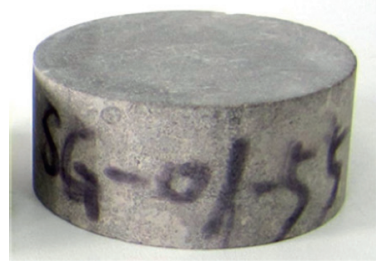

(d)

Figure 2: Apparent morphology of limestone specimens after high temperature. (a) $25^{\circ} \mathrm{C}$. (b) $200^{\circ} \mathrm{C}$. (c) $400^{\circ} \mathrm{C}$. (d) $600^{\circ} \mathrm{C}$.

\subsection{Changes in Volume, Mass, Density, and Longitudinal} Wave Velocity. According to the "Standard for test method of engineering rock mass" [32], the diameter, height, and quality of the limestone specimen after different temperature effects were measured and calculated, and the C61 type nonmetal ultrasonic detector was used to obtain its longitudinal wave velocity. The volume, mass, density, and longitudinal wave velocity of limestone specimen before and after the high temperature are shown in Figure 3.

It can be seen from Figure 3(a) that the limestone specimens showed volume expansion after different high-temperature effects, and the increase rate of volume increased with the increase of temperature. After $200^{\circ} \mathrm{C}, 400^{\circ} \mathrm{C}$, and $600^{\circ} \mathrm{C}$, the volume increased by $0.40 \%, 1.03 \%$, and $2.81 \%$, respectively, compared with that after room temperature. This phenomenon was caused by the volume expansion of the mineral particles composed of limestone due to high temperature, and the original micropores and microcracks inside the specimen began to germinate new cracks, which caused the expansion of specimen volume. After different high-temperature effects, the limestone specimens lost mass, and the mass reduction rate increased slightly with the increase of action temperature. After $200^{\circ} \mathrm{C}$ and $400^{\circ} \mathrm{C}$, the mass reduction rate of specimen was only $0.02 \%$ and $0.04 \%$, respectively. When the action temperature increased to $600^{\circ} \mathrm{C}$, the mass loss rate of rock specimen increased slightly, and the mass reduction rate was $0.97 \%$.
Figure 3(b) indicates that density of rock specimen decreased with increasing temperature after high temperature. The density of limestone specimens at room high temperature was $2.711-2.721 \mathrm{~g} / \mathrm{cm}^{3}$, while after $200^{\circ} \mathrm{C}$, $400^{\circ} \mathrm{C}$, and $600^{\circ} \mathrm{C}$, the average density was $2.711 \mathrm{~g} / \mathrm{cm}^{3}$, $2.692 \mathrm{~g} / \mathrm{cm}^{3}$, and $2.604 \mathrm{~g} / \mathrm{cm}^{3}$, which was $0.37 \%, 1.05 \%$, and $3.94 \%$ less compared with that after room temperature. Figure 3(c) shows that the longitudinal wave velocity of the limestone specimen without high-temperature effect ranged from $3975 \mathrm{~m} / \mathrm{s}$ to $4117 \mathrm{~m} / \mathrm{s}$. With the increase of temperature, the longitudinal wave velocity of the limestone specimen showed a downward trend. After $200^{\circ} \mathrm{C}$, the longitudinal wave velocity of the specimen was $3793 \mathrm{~m} / \mathrm{s}$, which was $7.87 \%$ less compared with that after room temperature. When the temperature increased to $400^{\circ} \mathrm{C}$ and $600^{\circ} \mathrm{C}$, the velocity of the longitudinal wave was reduced by $32.69 \%$ and $51.98 \%$, respectively. The main reasons could be concluded in two aspects: On one hand, due to the effect of high temperature, the constituent minerals inside the limestone specimen were expanded and new cracks were caused by different expansion coefficients. When the action temperature increased, the rock structure degradation degree increased, and powder particles appeared on the surface of the specimen. On the other hand, the pore volume caused by the evaporation of various types of water in the test piece increased. The increase of pores and the deterioration of 


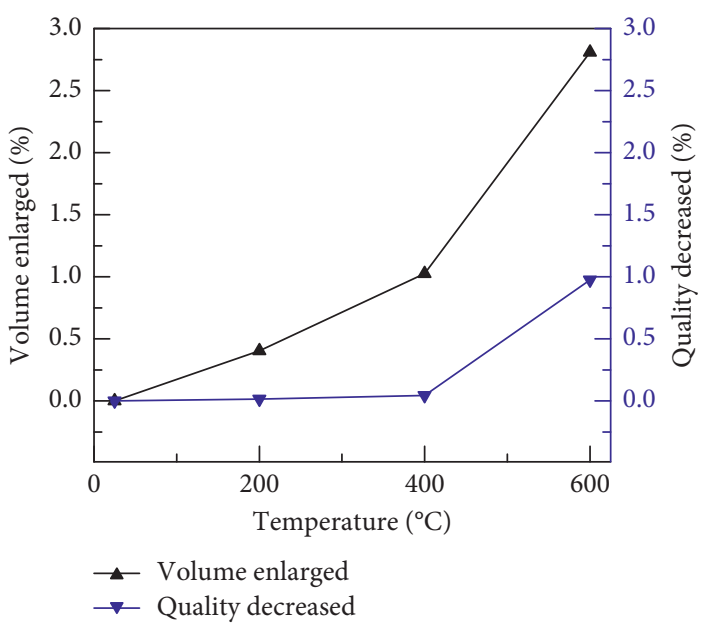

(a)

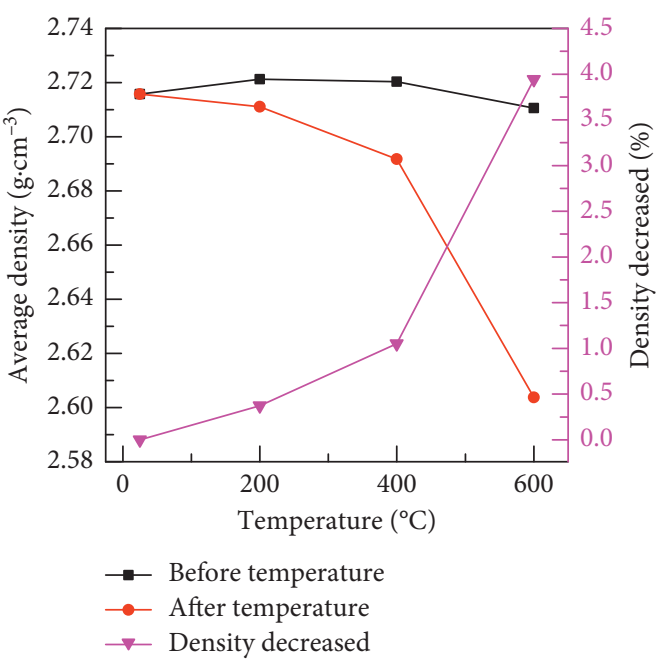

(b)

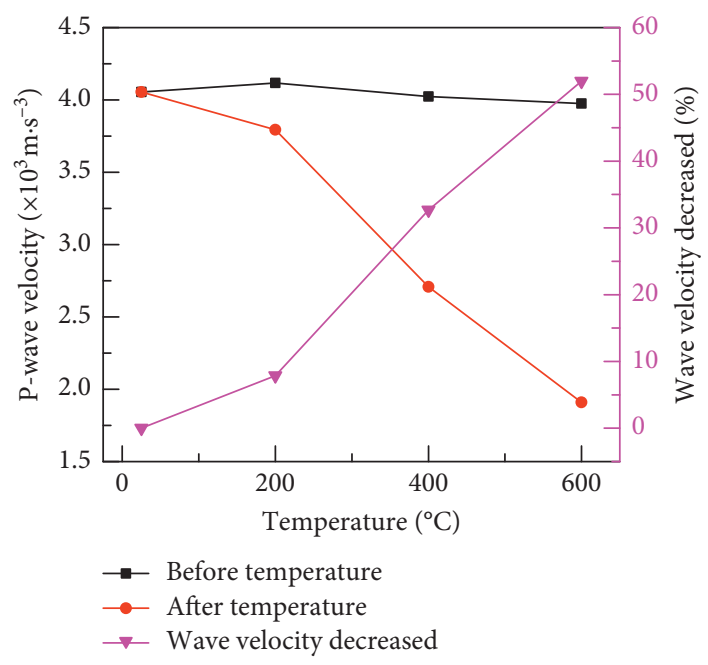

(c)

FIGURE 3: Relationship between basic physical parameters of limestone and temperature. (a) Volume and mass. (b) Density. (c) Longitudinal wave velocity.

internal structure caused by new cracks had a blocking effect on the propagation of stress waves, which caused the attenuation of stress wave propagation energy in the specimen and the decrease of wave velocity.

\section{The Basic Principle and Test Result of SHPB Test}

3.1. SHPB Test Device and Its Basic Principle. SHPB test device in the state key laboratory of mining response and disaster prevention and control in deep coal mine (as shown in Figure 4) was used to perform impact tests on limestone specimen with various temperature effects.

During SHPB test, the same impact velocity and loading waveform could be obtained using the same impact air pressure. When the incident stress pulse reached the interface between the incident bar and rock specimen, transmission and reflection occurred due to the different wave impedances. The stress pulse signal propagating in the pressure bar could be obtained from the strain gauges mounted on the incident and transmitted bar, respectively, as shown in Figure 5.

SHPB experimental principle was based on the assumption of one-dimensional stress wave and stress uniformity [33]. The three-wave method was used to obtain dynamic mechanical parameters such as stress $\sigma(t)$, strain $\varepsilon(t)$, and strain rate $\dot{\varepsilon}(t)$ of the specimen:

$$
\begin{aligned}
& \sigma(t)=\frac{A E}{2 A_{s}}\left[\varepsilon_{I}(t)+\varepsilon_{R}(t)+\varepsilon_{T}(t)\right], \\
& \varepsilon(t)=\frac{C}{L_{s}} \int_{0}^{\tau}\left[\varepsilon_{I}(t)-\varepsilon_{R}(t)-\varepsilon_{T}(t)\right] \mathrm{d} t, \\
& \dot{\varepsilon}(t)=\frac{C}{L_{s}}\left[\varepsilon_{I}(t)-\varepsilon_{R}(t)-\varepsilon_{T}(t)\right],
\end{aligned}
$$

where $A, E, C$ were the cross-sectional area, elastic modulus, and elastic longitudinal wave velocity of the compression 


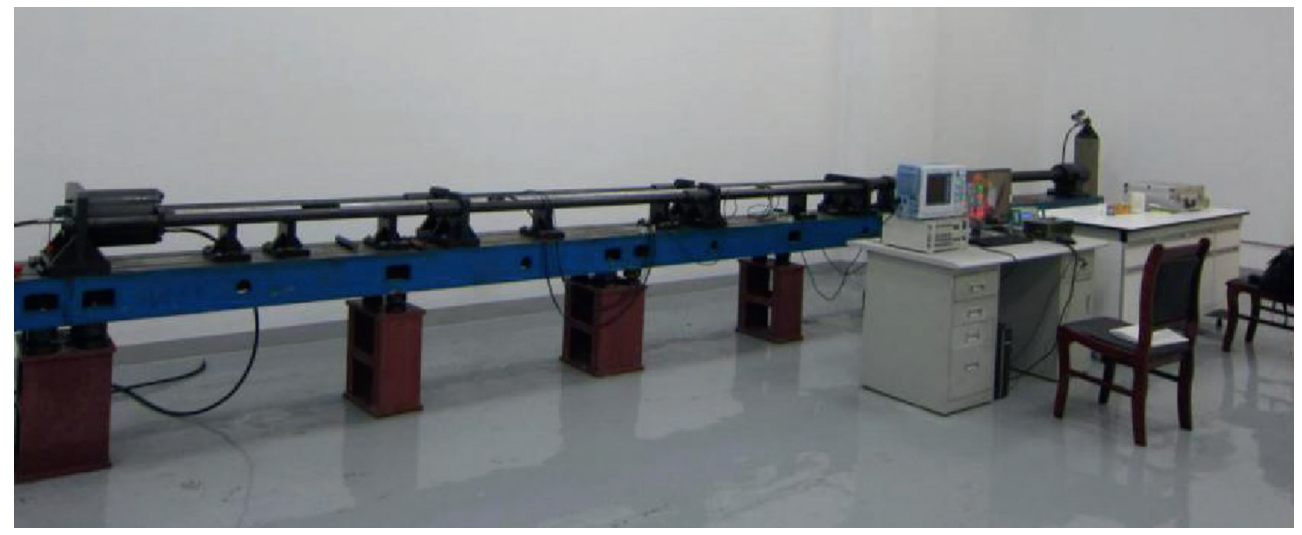

Figure 4: SHPB test device.

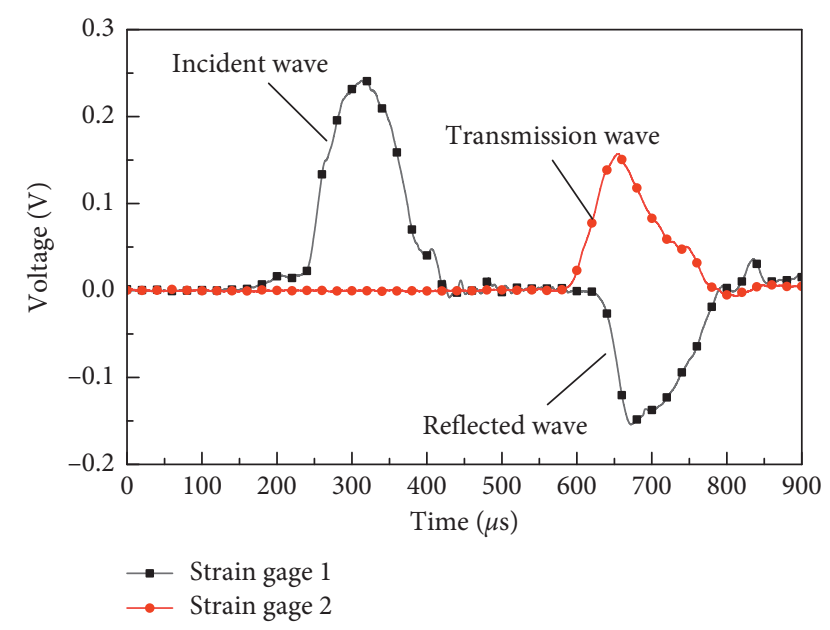

FIGURE 5: Measured strain signal in SHPB test of limestone specimen.

bar, respectively; $A_{S}$ and $L_{S}$ were the specimen cross-sectional area and specimen length, respectively; $\varepsilon_{I}(t), \varepsilon_{R}(t)$, and $\varepsilon_{T}(t)$ were the incident, reflected, and transmitted wave strain signals, respectively; $\tau$ was the duration of stress loading.

\subsection{Dynamic Compressive Stress-Strain Curves of Rock} Specimen. SHPB test device was used to carry out impact compression test with 6 kinds of impact gas pressures on the limestone specimen under room temperature $\left(25^{\circ} \mathrm{C}\right), 200^{\circ} \mathrm{C}$, $400^{\circ} \mathrm{C}$, and $600^{\circ} \mathrm{C}$. The dynamic compressive stress-strain curves of limestone specimen after different temperature effects were obtained and are shown in Figure 6.

Figure 6 reveals that the dynamic compressive stressstrain curves of limestone specimens after room and high temperature could be divided into three stages: elasticity stage, yield stage, and failure stage. In elastic stage, the relationship between stress and strain was proportional, and its slope increased with the increase of impact pressure; moreover, the ratio of elastic stage gradually decreased with the increase of temperature. In yield stage, the curve slope gradually decreased, and the slope of the curve was 0 when it reached the peak value; in addition, the decline rate of curve slope slowed down with the increase of temperature, and the ratio of yield stage gradually increased with the increase of temperature, which was due to the continuous evolution and development of fissures inside rock. Final, the internal cracks of the rock penetrated to form macrofailure and the slope of the curve was negative. The curves of limestone specimens showed upward trend with the increase of the impact pressure, and under the same loading conditions, the curve showed downward trend with the increase of the temperature.

3.3. Dynamic Failure Mode of Rock Specimen. The dynamic failure modes of rock specimens with various temperature effects are shown in Figure 7. It could be noticed that, for limestone specimens, after experiencing different high temperatures, the fragment failures were mainly sheet-shaped and axial splitting failure shape. Under the same action temperature, with the increase of impact air pressure, the incident energy generated increased, and the fracture surface of the specimen and degree of fragmentation gradually increased, while the size of the fragment decreased. Under the same impact pressure, the incident energy generated was basically the same, and the crushing degree of the specimen increased with the increase of temperature. The damage degree of limestone after $600^{\circ} \mathrm{C}$ high temperature was higher than the same loading condition at room temperature. When the impact gas pressure was relatively low, the limestone specimen could not be completely destroyed, and the number of fragments and specimen size was small. As the impact air pressure increased, the incident energy increased, and the fragmentation degree increased, the damage fragments were significantly increased, and the size of the fragments becomes significantly smaller. Under small impact air pressure, the incident energy acting on the specimen was relatively small. The random microcracks randomly distributed in the direction were developing in an orderly direction, and the number of broken blocks was small. With the incident energy acting on the test piece being increased, the cracks in the test piece were fully developed, resulting in a decreased size of fragments. 


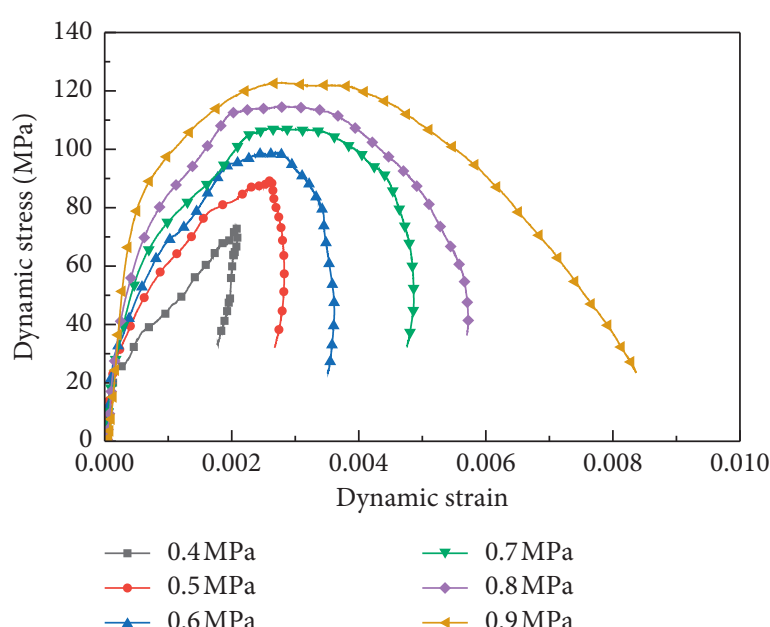

(a)

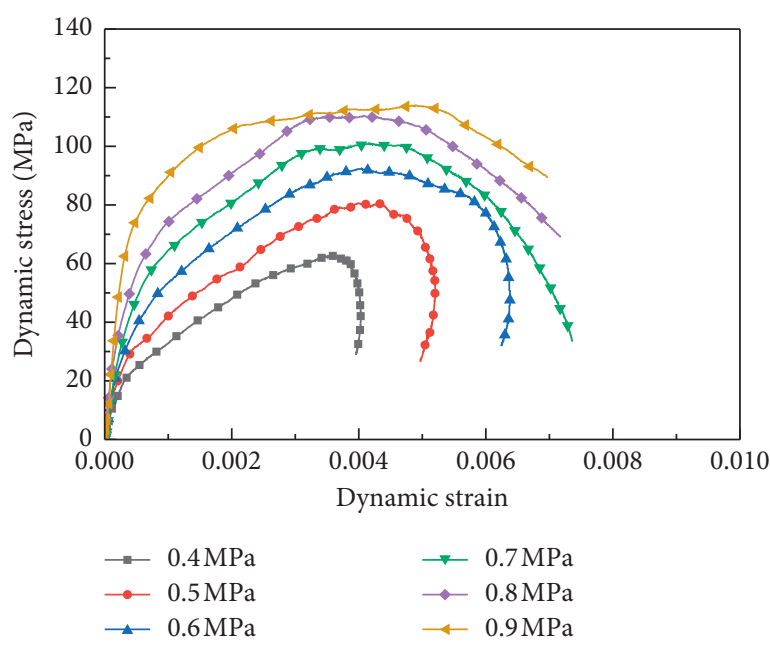

(c)

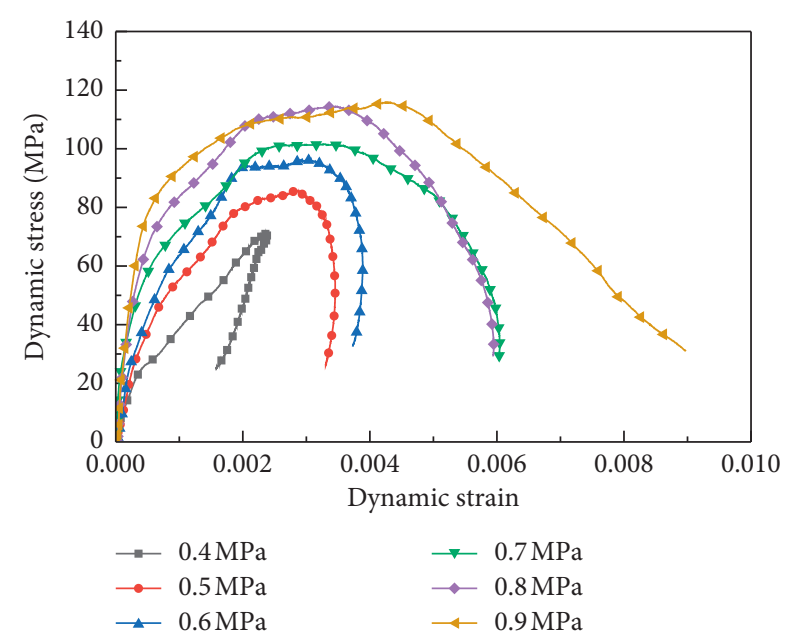

(b)

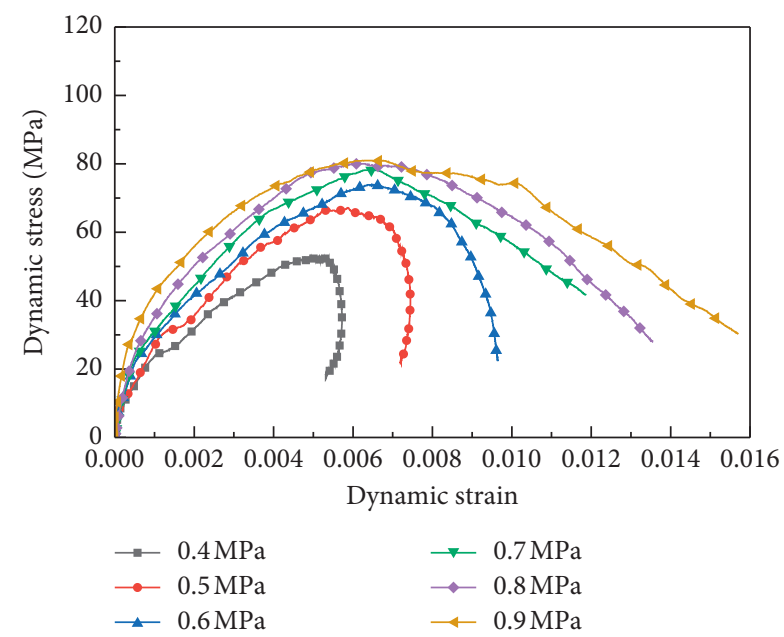

(d)

FiguRE 6: Dynamic compressive stress-strain curves of limestone specimen after different temperature effects. (a) $25^{\circ} \mathrm{C}$. (b) $200^{\circ} \mathrm{C}$. (c) $400^{\circ} \mathrm{C}$. (d) $600^{\circ} \mathrm{C}$.

\section{Dynamic Characteristic Parameters and Energy Evolution of SHPB Test}

4.1. Energy Composition in SHPB Test. In SHPB compressive tests, from the beginning of loading to the unloading process, the energy carried by the incident wave $\varepsilon_{I}(t)$, the reflected wave $\varepsilon_{R}(t)$, and the transmitted wave $\varepsilon_{T}(t)$ could be obtained by equation (2) $[34,35]$ :

$$
\left.\begin{array}{l}
E_{I}(t)=E_{0} C_{0} A_{0} \int_{0}^{\tau} \varepsilon_{I}^{2}(t) \mathrm{d} t, \\
E_{R}(t)=E_{0} C_{0} A_{0} \int_{0}^{\tau} \varepsilon_{R}^{2}(t) \mathrm{d} t, \\
E_{T}(t)=E_{0} C_{0} A_{0} \int_{0}^{\tau} \varepsilon_{T}^{2}(t) \mathrm{d} t,
\end{array}\right\}
$$

where $\varepsilon_{I}(t), \varepsilon_{R}(t)$ and $\varepsilon_{T}(t)$ were the incident energy, reflected energy, and transmitted energy, respectively.

In SHPB test, since the lubricant was applied on the contact surface between the rock specimen and the pressure rod, the energy consumed by the friction between the contact interfaces and between the specimen and the pressure rod could be ignored. Hence, according to the principle of energy conservation, the absorbed energy of limestone specimen could be obtained:

$$
E_{A}(t)=E_{I}(t)-\left[E_{R}(t)+E_{T}(t)\right] .
$$

The absorbed energy by the rock specimen was mainly dissipated in the following three aspects:

$$
E_{A}(t)=E_{F D}(t)+E_{K}(t)+E_{O}(t),
$$

where $E_{F D}(t)$ was energy consumption, mainly used for the propagation of original cracks inside the test piece and the generation of new fracture surfaces; $E_{K}(t)$ was ejection kinetic energy, mainly referring to the energy carried by the flying pieces of rock specimen. $E_{\mathrm{O}}(t)$ was another energy consumption, such as acoustic energy, thermal energy, radiant energy, and other forms of dissipated energy. 


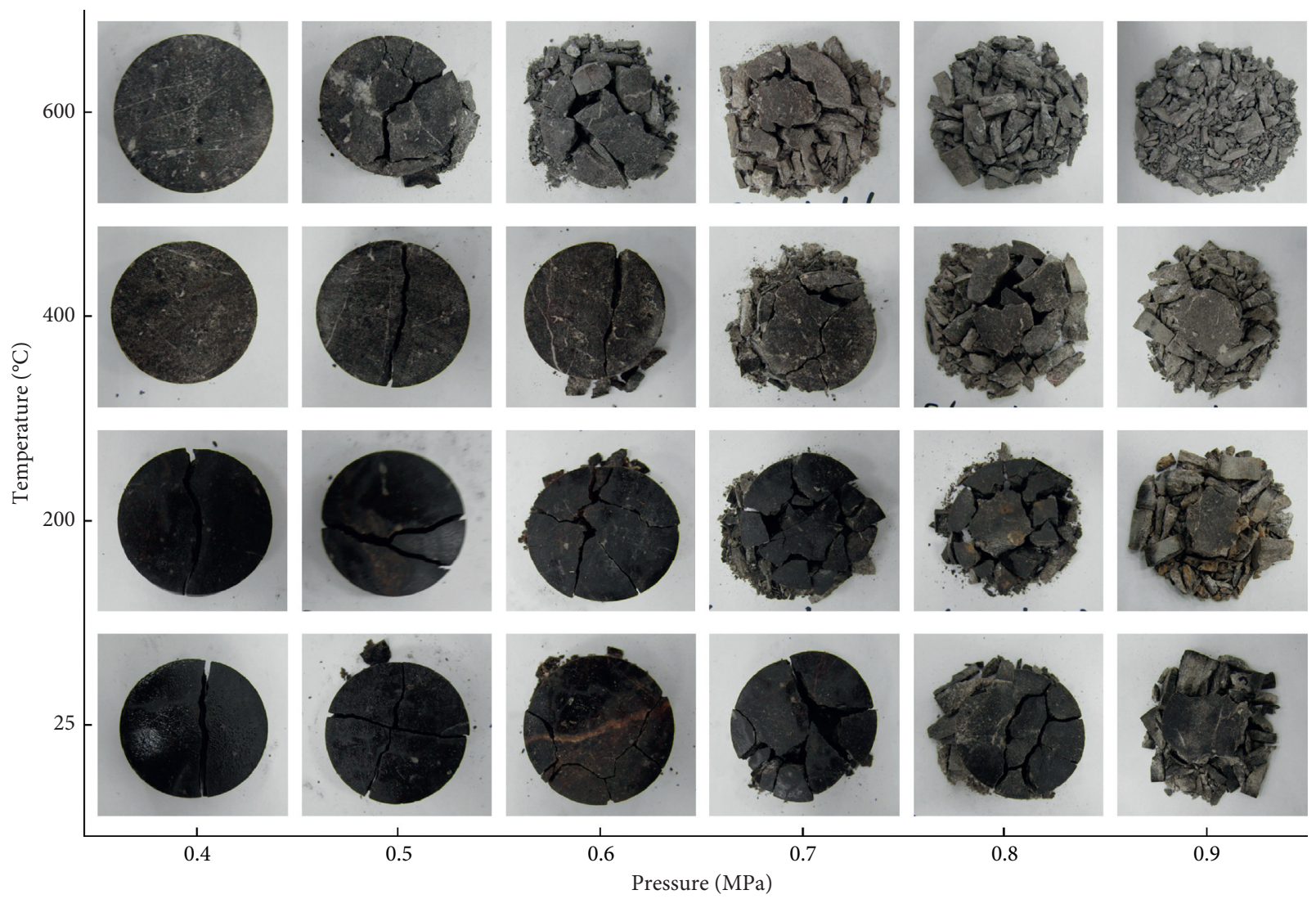

Figure 7: The failure modes of limestone specimen with various high temperatures under different impact air pressures.

Previous investigation showed that the ratio of $E_{\mathrm{O}}(t)$ was relatively small and could be ignored [36]; hence

$$
E_{A}(t)=E_{F D}(t)+E_{K}(t) \text {. }
$$

Zhang et al. and Hong $[37,38]$ found that $E_{F D}(t)$ was about $95 \%$ of $E_{S}(t)$; hence, the rock absorption energy $E_{A}(t)$ was used to replace rock energy consumption $E_{F D}(t)$.

4.2. Relationship between Energies in the SHPB Test. According to the obtained wave singles and calculation method, the incident energy, reflected energy, and transmitted energy of limestone specimen during the SHPB test could be calculated and are shown in Figure 8.

Figure 8 shows that incident energy, reflected energy, transmitted energy, and specimen absorbed energy all increased with the duration of loading, and the energy remains basically constant after reaching a certain value. The total incident wave loading time was about $207 \mu \mathrm{s}$. Figure 8 (a) indicates that, at low impact air pressure $(0.4 \mathrm{MPa})$, the transmission energy accounted for the largest proportion, about $71 \%$ of the incident energy, while the proportion of reflected energy was the smallest, only $4 \%$ of the incident energy. Moreover, the absorbed energy of the rock specimen was slightly higher than the reflected energy, accounting for about $24 \%$ of incident energy, and reached peak value at $133.2 \mu$ s. Figure 8 (b) illustrates that, at high-impact air pressure $(0.9 \mathrm{MPa})$, transmitted energy and reflected energy account for approximately $24 \%$ and $39 \%$ of the incident energy, respectively, and the absorption energy of specimen was about $37 \%$ of the incident energy, which reached peak value at $199.7 \mu \mathrm{s}$. For rock at room temperature $\left(25^{\circ} \mathrm{C}\right)$, under the low impact pressure, the degree of damage is small, and the energy absorbed by the specimen is relatively small. Most of the incident energy was transmitted to the transmitted bar through limestone specimen, and only a small part of them reflected to the incident bar. The rock specimen was damaged, caused by high temperature. After $600^{\circ} \mathrm{C}$, under the effect of higher-impact pressure, the destruction degree of the specimen was severe, and the energy absorbed by the specimen increased. Most of the incident energy reflected to the incident bar. Most of the energy absorbed by limestone specimen was dissipated in the damage evolution process of the microcrack; hence, the original disordered crack in the test piece gradually developed in an orderly direction, and finally a macroscopic main crack was formed, which led to the structure failure of test specimen.

When the SHPB test was carried out using 6 kinds of impact air pressures of $0.4 \mathrm{MPa}, 0.5 \mathrm{MPa}, 0.6 \mathrm{MPa}, 0.7 \mathrm{MPa}$, $0.8 \mathrm{MPa}$, and $0.9 \mathrm{MPa}$, the similar incident energy could be obtained under the same loading conditions, and the incident energy increased with the increase of impact air pressure, showing positive correlation, as shown in Figure 9.

Figure 10 shows the relationship among reflected energy, transmitted energy, and absorbed energy of limestone with incident energy. The reflected energy, transmitted energy, 


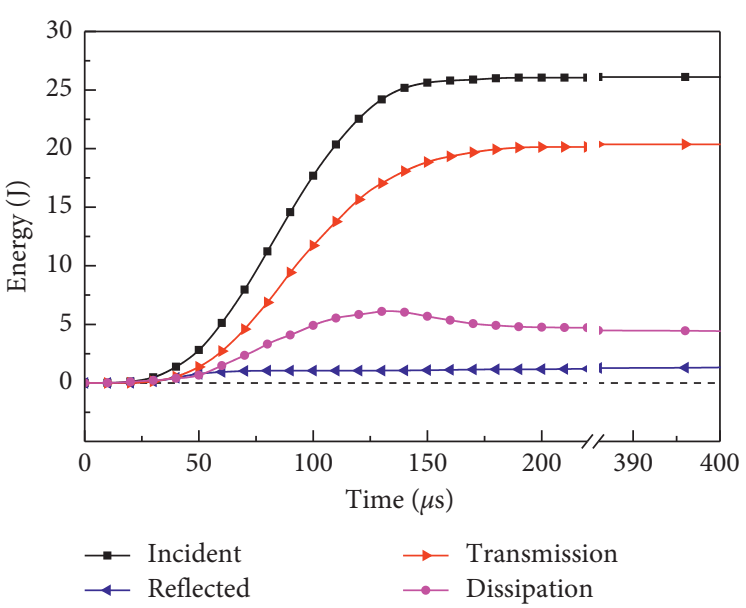

(a)

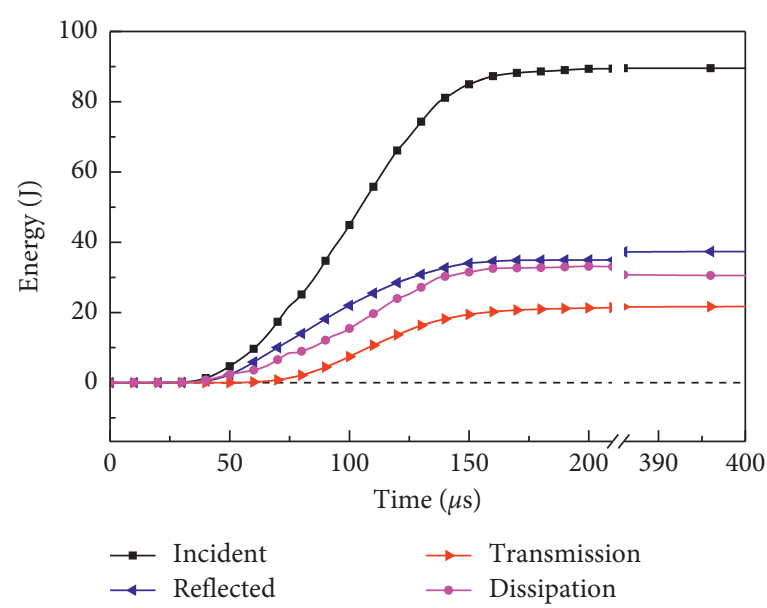

(b)

Figure 8: Time-history curve of energy change in SHPB compression test of limestone (a) $T=25^{\circ} \mathrm{C}, p=0.4 \mathrm{MPa}$. (b) $\mathrm{T}=600^{\circ} \mathrm{C}$, $p=0.9 \mathrm{MPa}$.

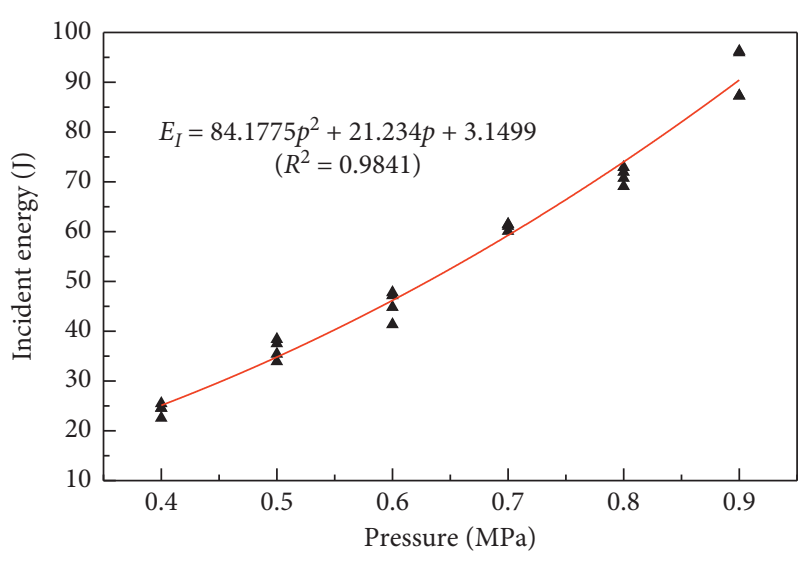

- Measured data

_ Fitting curve

FIGURE 9: Relationship between incident energy and impact air pressure.

and absorbed energy all increased with the increase of incident energy, showing quadratic function relationship, and the fitted minimum correlation coefficients were 0.9772 , 0.9273 , and 0.9607 , respectively.

Figure 10(a) revealed that, with the increase of temperature, the fitting curve of reflected energy and incident energy showed an upward trend, and the increase magnitude of reflected energy gradually increased with the increase of acting temperature. For example, the reflected energy of specimen at room temperature increased from $1.09 \mathrm{~J}$ to $7.25 \mathrm{~J}$, while the reflection energy of the specimen after the $600^{\circ} \mathrm{C}$ increased from $4.88 \mathrm{~J}$ to $34.95 \mathrm{~J}$. Figure $10(\mathrm{~b})$ indicated that, with the increase of temperature, the fitted curve of transmission energy and incident energy showed a downward trend, and the increase magnitude of reflected energy gradually decreased with the increase of temperature. After $600^{\circ} \mathrm{C}$, the transmission energy increased from $10.41 \mathrm{~J}$ to $23.77 \mathrm{~J}$ when the incident energy increased from $24.55 \mathrm{~J}$ to $95.95 \mathrm{~J}$. Figure 10(c) illustrates that, with the increase of incident energy, the increase gradient of absorbed energy of rock specimen after high temperature was basically the same.

4.3. Relationship between Dynamic Compressive Strength and Incident Energy. In this test, the dynamic compressive strength of limestone was defined as the peak dynamic stress in stress-strain curve. The dynamic compressive strength of limestone with various temperature effects is shown in Figure 11.

It could be observed from Figure 11 that the dynamic compressive strength of limestone specimens increased with increasing incident energy after different high-temperature effects, showing quadratic function relationship, as shown in

$$
\sigma_{T}=a E_{I}^{2}+b E_{I}+c
$$

where $\sigma_{T}$ was the dynamic compressive strength of limestone after high temperature, $\mathrm{MPa} ; a, b$ and $c$ were the fitting parameters, and their calculation values are shown in Table 1.

Figure 11 also indicates that the $\sigma_{T}-E_{I}$ fitting curve showed a downward trend with the increase of temperature, and the dynamic compression strength of the specimen decreased. The dynamic compressive strength decreased by $3.5 \%$ and $7.9 \%$ when the action temperature increased to $200^{\circ} \mathrm{C}$ and $400^{\circ} \mathrm{C}$, respectively. After $600^{\circ} \mathrm{C}$, the dynamic compressive strength was obviously reduced, with a $28.3 \%$ decrease amplitude. This was caused by the thermal stress expanding the microcracks inside the specimen and initiating new cracks, causing the deterioration of the internal structure of the rock specimen.

4.4. Relationship between Dynamic Elasticity Modulus and Incident Energy. The dynamic elasticity modulus of limestone with various temperature effects is shown in Figure 12.

Figure 12 shows that the dynamic elasticity modulus of limestone specimens increased with increasing incident 


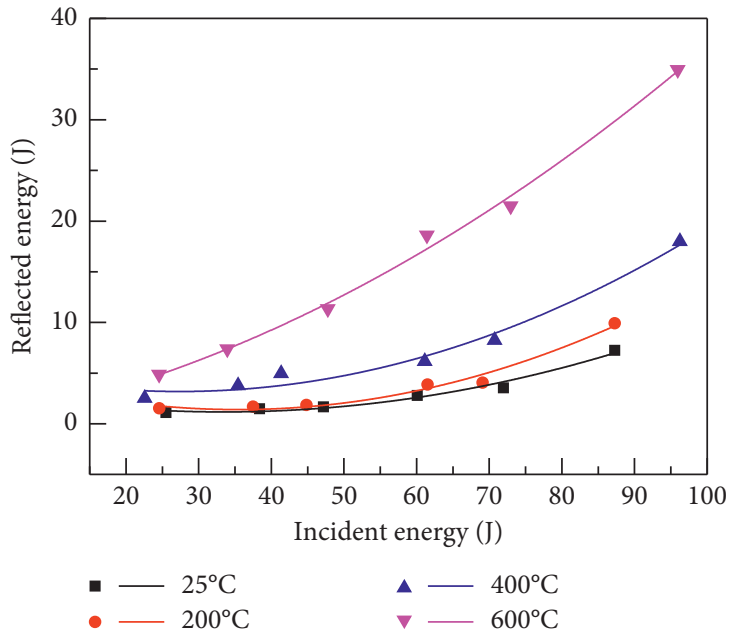

(a)

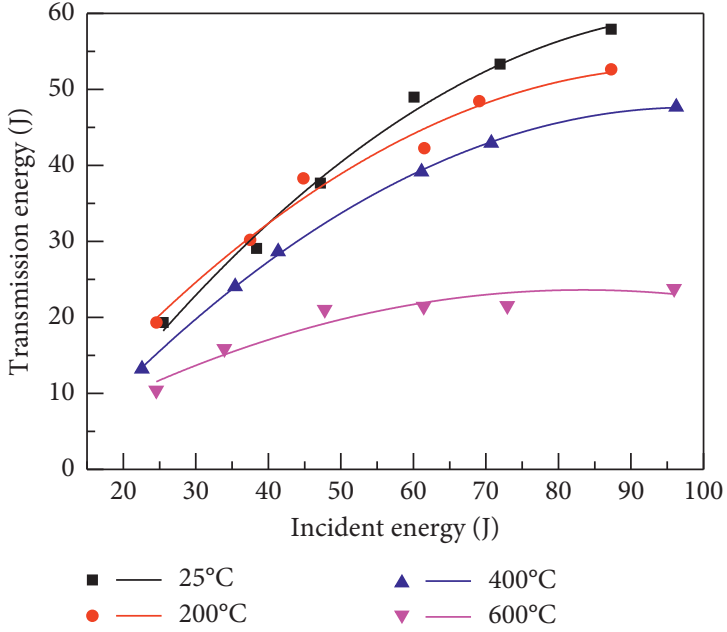

(b)

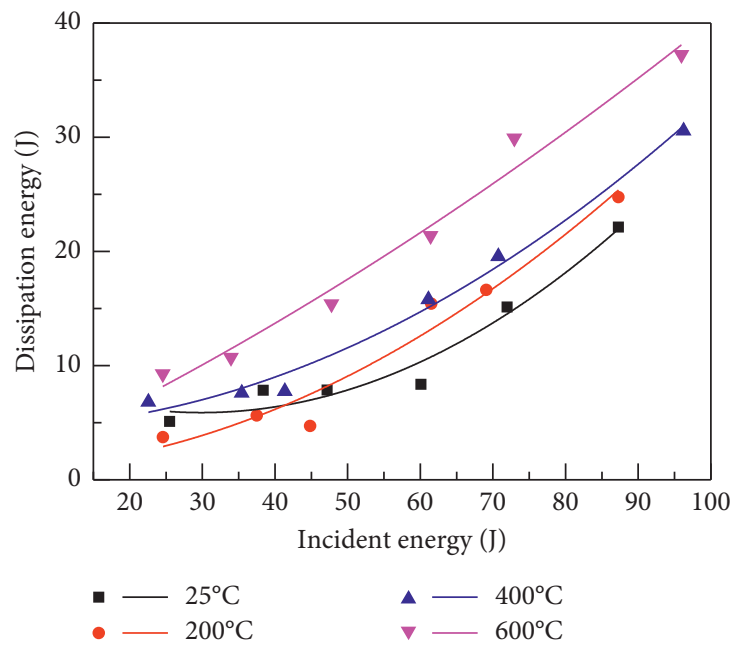

(c)

FiguRE 10: Relationship among reflected energy, transmitted energy, and absorbed energy of limestone with incident energy. (a) Reflected energy. (b) Transmission energy. (c) Dissipation energy (absorbed energy).

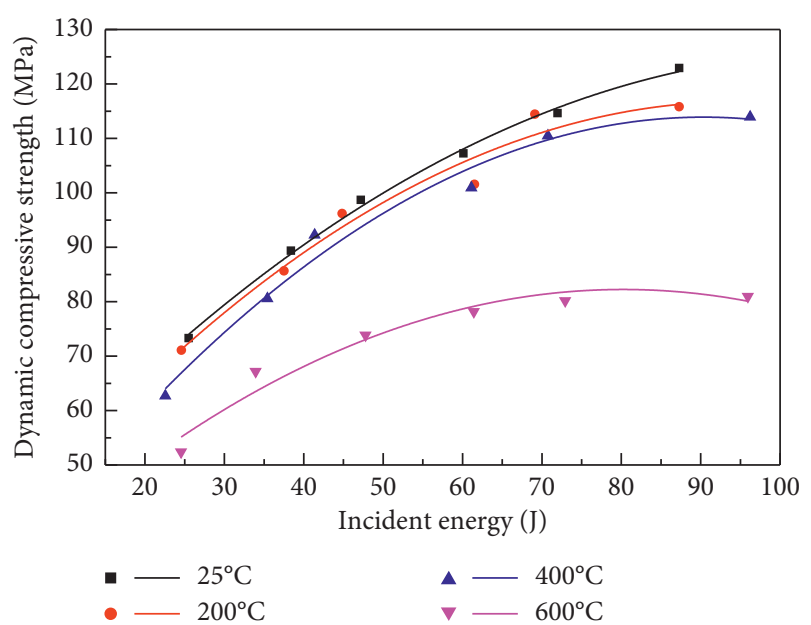

FIGURE 11: Relationship between dynamic compressive strength and incident energy.
TABle 1: Parameter values of dynamic compressive strength and incident energy.

\begin{tabular}{lcccc}
\hline$T\left({ }^{\circ} \mathrm{C}\right)$ & $a$ & $b$ & $c$ & Correlation coefficient $R^{2}$ \\
\hline 25 & -0.0075 & 1.6243 & 37.4229 & 0.9972 \\
200 & -0.0092 & 1.7498 & 33.7856 & 0.9688 \\
400 & -0.0109 & 1.9628 & 25.2459 & 0.9809 \\
600 & -0.0087 & 1.4030 & 25.9517 & 0.9565 \\
\hline
\end{tabular}

energy after different high-temperature effects, showing a quadratic function relationship, as shown in

$$
Y_{T}=d E_{I}^{2}+e E_{I}+f
$$

where $Y_{T}$ was the dynamic elasticity modulus of limestone after high temperature, GPa; $d, e$ and $f$ were the fitting parameters, and their calculation values are shown in Table 2. 


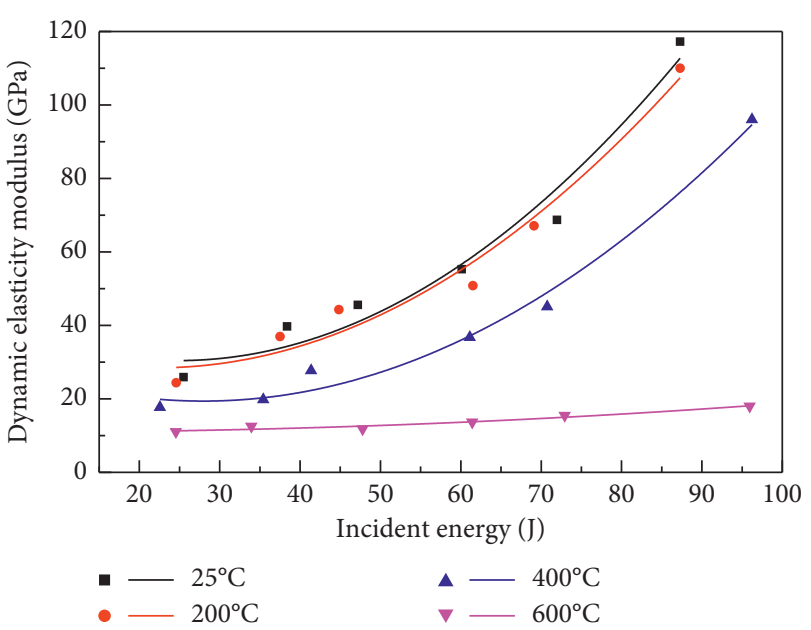

FIGURE 12: Relationship between dynamic elasticity modulus and incident energy.

TABle 2: Parameter values of dynamic elasticity modulus and incident energy.

\begin{tabular}{lcccc}
\hline$T\left({ }^{\circ} \mathrm{C}\right)$ & $d$ & $e$ & $f$ & Correlation coefficient $R^{2}$ \\
\hline 25 & 0.0211 & -1.0492 & 43.4581 & 0.9675 \\
200 & 0.0186 & -0.8274 & 37.6388 & 0.9719 \\
400 & 0.0161 & -0.9026 & 32.0116 & 0.9879 \\
600 & 0.0008 & -0.0048 & 10.9194 & 0.9524 \\
\hline
\end{tabular}

Figure 12 reveals that the $Y_{T}-E_{I}$ fitting curve showed a downward trend with the increase of temperature. The dynamic elasticity modulus decreased by $5.4 \%$ and $34.5 \%$ when the action temperature increased to $200^{\circ} \mathrm{C}$ and $400^{\circ} \mathrm{C}$, respectively. The dynamic elasticity modulus decreased, $72.9 \%$, after $600^{\circ} \mathrm{C}$. With the increase of the incident energy, dynamic elastic modulus of the limestone specimen increased rapidly at $25^{\circ} \mathrm{C}, 200^{\circ} \mathrm{C}$, and $400^{\circ} \mathrm{C}$. When the action temperature increased to $600^{\circ} \mathrm{C}$, the fitting curve approximates horizontal line, and the dynamic antielastic modulus was $11.03 \mathrm{GPa}-17.99 \mathrm{GPa}$, which was obviously reduced compared with that after room temperature. After hightemperature effect, the microcracks in the limestone specimen gradually expand, which reduced the ability of the specimen to resist deformation. In addition, when the action temperature exceeded a certain value, the internal mineral composition of the rock changed due to high temperature, which also weakened resist deformation ability of rock specimen.

4.5. Relationship between Dynamic Peak Strain and Incident Energy. The dynamic peak strain was the strain corresponding to peak stress; the dynamic peak strain of limestone with various temperature effects is shown in Figure 13. After the same temperature gradient, the dynamic peak strain of the specimen was not significantly affected by the incident energy, and the strain scopes were $2.07-2.79 \times 10^{-3}$, $2.34-4.24 \times 10^{-3}, 3.57-4.89 \times 10^{-3}$, and 5.29-6.46 $\times 10^{-3}$ after $25^{\circ} \mathrm{C}, 200^{\circ} \mathrm{C}, 400^{\circ} \mathrm{C}$, and $600^{\circ} \mathrm{C}$, respectively. However, dynamic peak strain increased with increasing temperature,

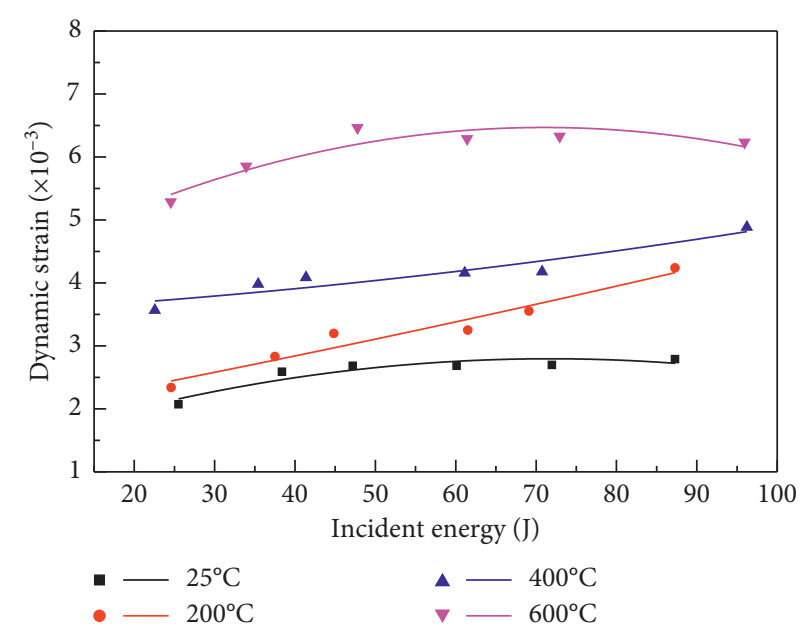

FIGURE 13: Relationship between dynamic peak strain and incident energy.

TABle 3: Parameter values of dynamic peak strain and incident energy.

\begin{tabular}{lcccc}
\hline$T\left({ }^{\circ} \mathrm{C}\right)$ & $i$ & $j$ & $k$ & Correlation coefficient $R^{2}$ \\
\hline 25 & $-2.98 E-4$ & 0.0428 & 1.2616 & 0.8629 \\
200 & $3.44 E-5$ & 0.0236 & 1.8426 & 0.9480 \\
400 & $6.78 E-5$ & 0.0069 & 3.5238 & 0.8906 \\
600 & $-4.93 E-4$ & 0.0700 & 3.9821 & 0.8658 \\
\hline
\end{tabular}

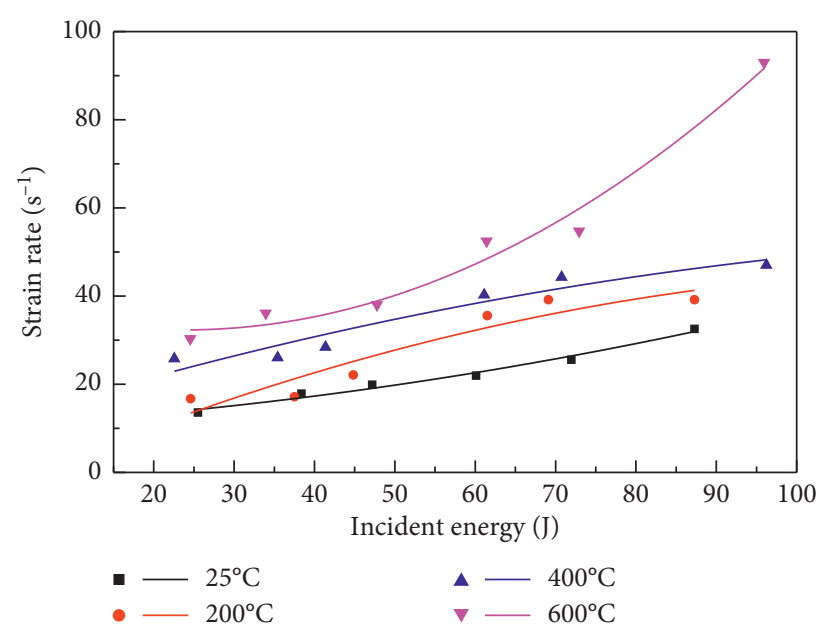

FIGURE 14: Relationship between strain rate and incident energy.

and the strain of limestone specimens after $200^{\circ} \mathrm{C}, 400^{\circ} \mathrm{C}$, and $600^{\circ} \mathrm{C}$ was 1.2 times, 1.6 times, and 2.4 times compared with that after room temperature.

After different temperatures, the dynamic strain of the limestone specimen increased with the increase of the incident energy, showing a quadratic function relationship:

$$
\varepsilon_{T}=i E_{I}^{2}+j E_{I}+k
$$

where $\varepsilon_{T}$ was the dynamic peak strain of limestone after high temperature, $\mathrm{GPa} ; i, j$ and $k$ were the fitting parameters, and their calculation values are shown in Table 3. 
TABLe 4: Parameter values of strain rate and incident energy.

\begin{tabular}{lcccc}
\hline$T\left({ }^{\circ} \mathrm{C}\right)$ & $i$ & $j$ & $k$ & Correlation coefficient $R^{2}$ \\
\hline 25 & 0.0016 & 0.1018 & 10.6275 & 0.9835 \\
200 & -0.0032 & 0.7980 & -4.2451 & 0.8976 \\
400 & -0.0019 & 0.5652 & 11.1425 & 0.9258 \\
600 & 0.0114 & -0.5429 & 38.7897 & 0.9785 \\
\hline
\end{tabular}

4.6. Relationship between Energy Dissipation and Strain Rate. The relationship between strain rate and incident energy is shown in Figure 14.

The strain rate of limestone specimen increased with the increase of incident energy after different high temperatures, which showed a quadratic function relationship, as shown in

$$
\dot{\varepsilon}_{T}=l E_{I}^{2}+m E_{I}+n
$$

where $\dot{\varepsilon}_{T}$ was the strain rate of limestone after high temperature, $\mathrm{s}^{-1} ; l, m$ and $n$ were the fitting parameters, and their calculation values are shown in Table 4.

\section{Conclusions}

The SHPB test device was used to perform compression tests on limestone after $25^{\circ} \mathrm{C}, 200^{\circ} \mathrm{C}, 400^{\circ} \mathrm{C}$, and $600^{\circ} \mathrm{C}$ with 6 impact air pressures. The effects of high temperature on the basic physical properties, dynamic characteristic parameters, and energy of limestone specimens were analyzed.

(1) The color of limestone specimen at room temperature was gray-black, and the specimens become gray-white after high temperature. When the action temperature increased to $600^{\circ} \mathrm{C}$, powder particles appeared on the surface of rock specimen, which showed that the high temperature effect damages the limestone structure. With the increase of temperature, the volume of the limestone specimen increased, while the mass, density, and longitudinal wave velocity decreased.

(2) The dynamic compressive stress-strain curve of limestone specimens after different high-temperature effects could be divided into elasticity stage, yield stage, and failure stage. Under the same temperature gradient, the curve showed upward trend with the increase of impact air pressure, while the curve shows a downward trend with the increase of the temperature

(3) The limestone specimen failure with exfoliated axial splitting, and the crushing degree of specimen increased with the increase of temperature. The reflected energy, transmitted energy, and absorbed energy increased with the increase of incident energy, showing a quadratic function relationship. The dynamic compressive strength, dynamic elastic modulus, dynamic peak strain, and strain rate of limestone specimens all increased with the increase of incident energy, showing a quadratic function relationship.

\section{Data Availability}

The datasets generated and analyzed during the current study are available from the corresponding author upon reasonable request.

\section{Conflicts of Interest}

The authors declare that there are no conflicts of interest regarding the publication of this paper.

\section{Acknowledgments}

This research received financial supports from the National Natural Science Foundation of China (No. 51674008), Anhui Provincial Natural Science Foundation (No. 1808085ME134), and Anhui Postdoctoral Science Foundation (No. 2015B058). Thanks are due to the Engineering Research Center of Underground Mine Construction, Ministry of Education, and Anhui University of Science and Technology, State Key Laboratory of Mining Response and Disaster Prevention and Control in Deep Coal Mine, for providing the experiment conditions.

\section{References}

[1] S. Liu and J. Xu, "Investigation of impact compressive mechanical properties of sandstone after as well as under high temperature," High Temperature Materials and Processes, vol. 33, no. 6, pp. 585-591, 2014.

[2] W. Yao, Y. Xu, W. Wang, and P. Kanopolous, "Dependence of dynamic tensile strength of longyou sandstone on heattreatment temperature and loading rate," Rock Mechanics and Rock Engineering, vol. 49, no. 10, pp. 3899-3915, 2016.

[3] Z. L. Wang and G. Y. Shi, "Effect of heat treatment on dynamic tensile strength and damage behavior of medium-finegrained huashan granite," Experimental Techniques, vol. 41, no. 4, pp. 365-375, 2017.

[4] L. L. Cao, H. Pu, P. T. Qiu, and L. Zhang, "Analyzing creeping properties of mudstone at high temperature based on variable-order fractional calculus," Journal of Mining \& Safety Engineering, vol. 34, no. 1, pp. 148-154, 2017.

[5] R. Lei, Y. Wang, L. Zhang et al., "The evolution of sandstone microstructure and mechanical properties with thermal damage," Energy Science \& Engineering, vol. 7, no. 6, pp. 3058-3075, 2019.

[6] S. Liu and J. Xu, "Effect of strain rate on the dynamic compressive mechanical behaviors of rock material subjected to high temperatures," Mechanics of Materials, vol. 82, pp. 28-38, 2015.

[7] B. P. Xi, Y. C. Wu, S. Wang, G. Xiong, and Y. s. ZHAO, "Experimental study on mechanical properties of granite taken from Gonghe basin, Qinghai province after high temperature thermal damage," Chinese Journal of Rock Mechanics and Engineering, vol. 39, no. 1, pp. 69-83, 2020.

[8] C. D. Su, S. J. Wei, B. D. Qin, and Y. Yu-shun, "Experimental study of influence mechanism of high temperature on mechanical properties of fine-grained sandstone," Rock and Soil Mechanics, vol. 38, no. 3, pp. 623-630, 2017.

[9] X. L. Xu, F. Gao, and Z. Z. Zhang, "Influence of confining pressure on deformation and strength properties of granite after high temperatures," Chinese Journal of Geotechnical Engineering, vol. 36, no. 12, pp. 2246-2252, 2014.

[10] T. Yin, L. Bai, X. Li, X. Li, and S. Zhang, "Effect of thermal treatment on the mode I fracture toughness of granite under dynamic and static coupling load," Engineering Fracture Mechanics, vol. 199, pp. 143-158, 2018.

[11] Z. L. Wang, H. Shi, and J. G. Wang, "Mechanical behavior and damage constitutive model of granite under coupling of 
temperature and dynamic loading," Rock Mechanics and Rock Engineering, vol. 51, no. 10, pp. 3045-3059, 2018.

[12] L. N. Y. Wong, Z. Li, H. M. Kang, and C. I. Teh, "Dynamic loading of carrara marble in a heated state," Rock Mechanics and Rock Engineering, vol. 50, no. 6, pp. 1487-1505, 2017.

[13] S. Liu and J. Xu, "Study on dynamic characteristics of marble under impact loading and high temperature," International Journal of Rock Mechanics and Mining Sciences, vol. 62, pp. 51-58, 2013.

[14] Q. Ping, Z. H. Fang, D. D. Ma, and H. Zhang, "Coupled staticdynamic tensile mechanical properties and energy dissipation characteristic of limestone specimen in SHPB tests," Advances in Civil Engineering, vol. 2020, Article ID 7172928, 11 pages, 2020.

[15] G. Wu, N. G. Teng, and Y. Wang, "Physical and mechanical characteristics of limestone after high temperature," Chinese Journal of Geotechnical Engineering, vol. 33, no. 2, pp. 259264, 2011.

[16] Q.-b. Meng, W. Qian, J.-f. Liu, M.-w. Zhang, M.-m. Lu, and $\mathrm{Y}$. Wu, "Analysis of triaxial compression deformation and strength characteristics of limestone after high temperature," Arabian Journal of Geosciences, vol. 13, no. 4, 2020.

[17] Q. Ping, M. J. Wu, P. Yuan et al., "Experimental study on dynamic mechanical properties of sandstone under coupled actual high temperature and impact loads," Chinese Journal of Rock Mechanics and Engineering, vol. 38, no. 4, pp. 782-792, 2019.

[18] Q. Ping, M. J. Wu, H. Zhang et al., "Experimental study on dynamic mechanical characteristics of sandstone under actual high temperature conditions," Chinese Journal of Underground Space and Engineering, vol. 15, no. 3, pp. 691-698, 2019.

[19] Q. Sun, C. Lü, L. Cao, W. Li, J. Geng, and W. Zhang, "Thermal properties of sandstone after treatment at high temperature," International Journal of Rock Mechanics and Mining Sciences, vol. 85, pp. 60-66, 2016.

[20] T. B. Yin, X. B. Li, W. Z. Cao et al., "Effects of thermal treatment on tensile strength of laurentian granite using Brazilian test," Rock Mechanics and Rock Engineering, vol. 48, no. 6, pp. 2212-2223, 2015.

[21] P. Wang, J. Xu, X. Fang, and P. Wang, "Energy dissipation and damage evolution analyses for the dynamic compression failure process of red-sandstone after freeze-thaw cycles," Engineering Geology, vol. 221, pp. 104-113, 2017.

[22] L. F. Fan, Z. L. Wu, Z. Wang, Z. J. Wu, Z. Wan, and J. W. Gao, "Experimental investigation of thermal effects on dynamic behavior of granite," Applied Thermal Engineering, vol. 125, pp. 94-103, 2017.

[23] S. Liu and J. Xu, "An experimental study on the physicomechanical properties of two post-high-temperature rocks," Engineering Geology, vol. 185, pp. 63-70, 2015.

[24] S. Liu and J. Xu, "Mechanical properties of Qinling biotite granite after high temperature treatment," International Journal of Rock Mechanics and Mining Sciences, vol. 71, pp. 188-193, 2014.

[25] Z. Yin, W. Chen, H. Hao et al., "Dynamic compressive test of gas-containing coal using a modified split Hopkinson pressure bar system," Rock Mechanics and Rock Engineering, vol. 53, no. 2, pp. 815-829, 2020.

[26] Z. Q. Yin, Z. Hu, Z. D. Wei et al., "Assessment of blastinginduced ground vibration in an open-pit mine under different rock properties," Advances in Civil Engineering, vol. 2018, Article ID 4603687, 10 pages, 2018.
[27] K. Peng, J. Zhou, Q. Zou, and F. Yan, "Deformation characteristics of sandstones during cyclic loading and unloading with varying lower limits of stress under different confining pressures," International Journal of Fatigue, vol. 127, pp. 82-100, 2019.

[28] T. Yin, X. Li, K. Xia, and S. Huang, "Effect of thermal treatment on the dynamic fracture toughness of laurentian granite," Rock Mechanics and Rock Engineering, vol. 45, no. 6, pp. 1087-1094, 2012.

[29] The National Standards Compilation Group of the People's Republic of China, "Code for investigation of geotechnical engineering," China Architecture and Building Press, Beijing, China, GB50021-2019, 2019.

[30] R. Ulusay, The ISRM Suggested Methods for Rock Characterization, Testing and Monitoring; 2007-2014, pp. 51-68, Springer International Publishing, Cham, Switzerland, 2015.

[31] Chinese Society for Rock Mechanics \& Engineering, "Technical specification for testing method of rock dynamic properties[EB/OL]," T/CSRME 001-2019, 2019, http://www. ttbz.org.cn/Home/Show/10253.

[32] The National Standards Compilation Group of the People's Republic of China, "Standard for test method of engineering rock mass,” GB/T50266-2013, China Planning Publishing House, Beijing, China, 2013.

[33] L. L. Wang, Foundation of Stress waves, pp. 39-64, National Defense Industry Press, Beijing, Chian, 2nd edition, 2010.

[34] R. R. Zhang, L. W. Jing, and Q. Y. Ma, "Experimental study on thermal damage and energy evolution of sandstone after high temperature treatment," Shock and Vibration, vol. 2018, Article ID 3845353, 9 pages, 2018.

[35] R. R. Zhang and P. Yuan, "Effect of hydrothermal coupling on physical and dynamic mechanical properties of sandstone," Advances in Civil Engineering, vol. 2019, Article ID 7318768, 14 pages, 2019.

[36] S. Liu, J. Y. Xu, J. Z. Liu et al., "Analysis on energy of sericitequartz schist and sandstone in the dy-namic fracture process," Chinese Journal of Under-ground Space and Engineering, vol. 7, no. 6, pp. 1181-1185, 2011.

[37] Z. X. Zhang, S. Q. Kou, L. G. Jiang, L. G. Jiang, and P.-A. Lindqvist, "Effects of loading rate on rock fracture: fracture characteristics and energy partitioning," International Journal of Rock Mechanics and Mining Sciences, vol. 37, no. 5, pp. 745-762, 2000.

[38] L. Hong, "Size effect on strength and energy dissipation in fracture of rock under impact loads," Ph. D. thesis, Central South University, Changsha, China, 2008. 